\title{
Managing Customer Relationships in the Emerging Markets - Guanxi as a Driver of
}

\section{Chinese Customer Loyalty}

\begin{abstract}
Guanxi, a social exchange mechanism built on mutual favors, is an integral part of Chinese culture and a necessary relationship management tool for businesses operating in the People's Republic of China (PRC). This paper uses the cognition-affect-conation trajectory to illustrate the subtle differences between Guanxi approach and the conventional relationship marketing approaches on customer loyalty and word-of-mouth intentions. This process is mediated by calculative trust and affective attitude toward the service provider, while operationalizing the in-group identification construct to gauge in-group membership. Findings from a field-survey with Chinese retail-banking customers $(\mathrm{N}=420)$ support most of the hypotheses. Besides extending relationship marketing literature by highlighting the need to incorporate unique aspects of different cultures (especially in the emerging markets), this paper also provides many useful managerial implications and directions for future research on phenomena similar to Guanxi (e.g., "blat" in Russia, "wa" in Japan and "inhwa" in Korea).
\end{abstract}

Keywords: Guanxi; Relationship Marketing; Customer Loyalty; Word-of-mouth; Calculative Trust; Social Ties 


\section{INTRODUCTION}

Relationship marketing is an important topic in marketing theory because of its crucial role in helping develop and maintain mutually profitable and sustainable relationships among buyers and sellers (Gruen, Summers, \& Acito, 2000; Morgan \& Hunt, 1994; Samaha, Beck, \& Palmatier, 2014). In this context, a recent meta-analysis of 170 studies in 36 countries reveals significant differences in the effects of relational mediators such as trust and commitment across different cultures (Samaha et al., 2014). However, there is not much research into the underlying socio-cultural mechanisms that may drive these differences, such as some unique cultural factors that drive relationship marketing process around the world (Gap 1).

Interestingly, there is also a large body of research on Guanxi, a social exchange mechanism built on mutual favors, which is considered an important strategic asset by most Chinese people and businesses (Davies, Leung, Luk, \& Wong, 1995; Park \& Luo, 2001). Guanxi has played a major role in the Chinese society throughout its long history (Alston, 1989) and the modernization and globalization of the Chinese economy in the last few decades has even forced multinational companies to look for ways to establish their own Guanxi networks in China (Davies et al., 1995). However, despite some attempts to compare the concepts of relationship marketing and Guanxi (e.g., Ambler, Styles, \& Xiucun, 1999; Leung, Lai, Chan, \& Wong, 2005; Shaalan, Reast, Johnson, \& Tourky, 2013; Wong \& Chan, 
1999), the exact roles played by Guanxi and its underlying dimensions in mainstream

relationship marketing, particularly their impact on customer loyalty in the services context, are still not very clear or well-established (Gap 2).

People's Republic of China (PRC) is the most populous country in the world and the largest economy, as measured on purchasing power parity (PPP) basis, well ahead of United States and European Union (Central Intelligence Agency, 2016). China is also culturally very different from the Western countries, with strong collectivistic values and high long-term orientation (Hofstede, 2001). Hence, it is not surprising to see that international relationship marketing studies find Chinese firms twice as effective in using relationship marketing to drive performance as those in the United States (e.g., Samaha et al., 2014). However, despite growing evidence about the differences in the business and cultural practices between China and the rest of the world (Sharma, 2010), past research on relationship marketing, especially its impact on customer loyalty, has generally ignored China and focused on Western cultures (Sharma 2011) (Gap 3).

Finally, past research on the role of Guanxi in the Chinese context has mainly focused on buyer-seller relationships in the business-to-business (B2B) context and on organizational performance outcomes such as sales growth (e.g., Park \& Luo, 2001; Barnes, Leonidou, Siu, \& Leonidou, 2015; Barnes, Yen, \& Zhou, 2011; Leung, Chan, Lai, \& Ngai, 2011; Yang \& 
Wang, 2011). Samiee, Chabowski and Hult's (2015) meta-analysis of international crossborder relationship marketing studies also shows that most studies focus on B2B context with very few studies on business-to-consumer (B2C) relationships. Hence, it is not clear to what extent the same relationship marketing constructs and models can apply in B2B and B2C contexts, and what could be the theoretical differences between them (Gap 4).

This paper addresses all the above research gaps by exploring the link between relationship marketing and Guanxi with a focus on the services context in China, which is the largest emerging market in the world. To explore the role played by Guanxi in driving customer loyalty behavior in a services context, the authors develop and test a conceptual model using insights from many well-established but diverse perspectives, ranging from relationship marketing and customer loyalty to social ties in social networks and Guanxi. To summarize, this paper addresses the following specific research questions:

1. What role does Guanxi play in relationship marketing in the People's Republic of China, especially in terms of its impact on customer loyalty behaviors?

2. Which factors may mediate the impact of Guanxi on the customer loyalty behaviors in the People's Republic of China?

This paper begins with a review of extant research on relationship marketing and Guanxi, with a focus on the services context. Next, it develops specific hypotheses about the process 
by which Guanxi and in-group identification affect both short- and long-term customer

loyalty behavioral intentions and the mediating role of calculative trust and affective attitudes towards the target object in this process. Next, the paper describes a field-survey with 420 retail banking customers in China, which shows support for most of the hypotheses. Finally, the authors discuss the theoretical contribution and managerial implications of their findings along with some limitations of their study and directions for future research.

\section{THEORETICAL BACKGROUND AND HYPOTHESES}

\section{Guanxi and Relationship Marketing}

Guanxi is a major part of Chinese culture, known since the time of Confucius (551-479 BC), the philosopher whose ideas form the basis of modern Chinese business and cultural practices (Dawson, 2005). Guanxi in the business context represents the "durable social connections and networks a firm uses to exchange favors for organizational purposes" (Gu, Hung, \& Tse, 2008, p.12). However, there is no literal translation or consistent understanding of the term Guanxi in the Western cultures (Haley, Haley, \& Tan, 2004; Tsui \& Farh, 1997).

The conceptual definition of Guanxi has evolved from a unidimensional construct based on early qualitative and descriptive studies (e.g., Davies et al. 1995) to a more complex multidimensional measurement construct (e.g., Yen, Barnes, \& Wang, 2011), consisting of three dimensions, namely renqing, xinren and ganqing. Renqing is a set of social norms used 
by the members of a network as a coping strategy to maintain harmony within their social circle (Hwang, 1987; Leung, Heung, \& Wong, 2008; Wang, 2007). Xinren relates to the trustworthiness aspect of Guanxi that is considered as a credit (Chen \& Chen, 2004). Ganqing represents shared feelings among the members of a network that indicate the closeness of Guanxi (Wang, 2007, p.82). All these dimensions are operationalized as three sub-scales that are used to measure the Guanxi construct in empirical studies with quantitative methodologies (Chen \& Chen, 2004; Kipnis, 1997; Wang, 2007; Yen et al., 2011).

While Guanxi is clearly a well-entrenched traditional way in which relationships are created and managed in Chinese culture, the modern view of relationship marketing has focused on its role in helping businesses develop and maintain meaningful relationships with their customers (Morgan \& Hunt, 1994). A recent meta-analysis of 170 studies across 36 countries shows many cross-cultural differences in the impact of important constructs such as trust and commitment (Samaha et al., 2014); however, it only makes a passing reference to Guanxi and cites only one study (Lee \& Dawes, 2005). Therefore, it seems very important to understand the conceptual overlap between the traditional concepts such as Guanxi and the relatively more modern ones, such as relationship marketing.

In fact, there are a few studies that do examine the similarities and differences between Guanxi and relationship marketing (e.g., Tomás Gómez Arias, 1998; Ambler, Styles, 
\& Xiucun, 1999; Leung, Lai, Chan, \& Wong, 2005; Shaalan, Reast, Johnson, \& Tourky, 2013; Wang, 2007; Wong \& Chan, 1999; Yau, Lee, Chow, Sin, \& Tse, 2000). For example, Shaalan et al. (2013) describe Guanxi as a set of affective, implicit, personal and tactical trust-based relationships among the members of a social network, and relationship marketing as a calculative, explicit, impersonal and strategic relationships among the members of a business network. Others focus on the differences in the nature of relationships Tomás Gómez Arias, 1998), focus on long-term versus transactional relationships (Wang, 2007) and the emphasis on "bonding, reciprocity, trust and empathy" in Guanxi (Yau et. al., 2000, p.20).

Differences between Guanxi and relationship marketing can be grouped in three major categories. First, there is no consensus on which relational constructs drive customer loyalty in these two perspectives. Generally, trust, satisfaction and commitment are most common in relationship marketing discipline (Palmatier, Dant, Grewal, \& Evans, 2006); whereas Guanxi researchers use a more complex and nuanced view by decomposing it into its three dimensions, namely renqing (reciprocity), ganqing (bonding and empathy) and xinren (trust). Apart from this multidimensional nature of Guanxi (ganqing, xinren and renqing), Shaalan et al. (2013) also highlight that face-saving is the motive for reciprocity in Guanxi, whereas it is mutuality in relationship marketing. In addition, affection, face and mutual trust are also identified as unique features in relationship marketing studies with Chinese consumers (Tomás Gómez Arias, 1998). These findings suggest that it may be useful to use 
Guanxi as one of the key relationship marketing mechanisms in China, rather than rely only on the more popular relationship marketing process developed in the Western cultures.

Second, relationship marketing studies focus on relationships within dyads, (Björkman \& Kock, 1995) while Guanxi studies focus on relationships within personal networks and on social exchanges (Björkman \& Kock, 1995; Tomás Gómez Arias, 1998). Shaalan et al. (2013) use network theory to describe Guanxi as an individualistic and particularistic system formed within a closed social network (Farh, Tsui, Xin, \& Cheng, 1998) and relationship marketing as an open, institutional, universalistic and impersonal system.

Third, in relationship marketing, loyalty develops over time and goes through different stages (Dick \& Basu, 1994), under the impact of various marketing actions (Ngobo, 2016). However, Guanxi is tactical in orientation, whereas relationship marketing is strategic. Exchange, relational and commitment behaviors in Guanxi involve implicit favors, affection and promises with undefined timelines, whereas relationship marketing is commercial, economic, calculative, cooperative and explicit, with clear deadlines (Shaalan et al., 2013; Tomás Gómez Arias, 1998).

All these differences between Guanxi and relationship marketing approaches highlight the need for more research in order to provide a deeper understanding of the process 
by which Guanxi affects customer loyalty behavior, especially due to the implicit and yet particularistic nature of interpersonal relationships under Guanxi. Research on relationship marketing shows that it has a strong impact on loyalty and profitability (Reichheld, 1990); hence, a study of Guanxi's impact on loyalty behaviors would extend our knowledge of relationship marketing and buying behavior in an emerging market like China, where Guanxi is the most prevalent social exchange mechanism that drives most interpersonal relationships.

\section{Ego-pragmatic Perspective of Guanxi}

Chen et al. (2013) summarize three theoretical perspectives of Guanxi; ego-pragmatic, community-ethical, and Confucian relational. The ego-pragmatic perspective of Guanxi, considers Guanxi as a strategic or tactical tool used for enhancing business and organizational competitiveness (e.g., Park \& Luo, 2001; Peng \& Luo, 2000). As Guanxi ties and networks are ego-enhancing, this perspective reveals how one benefits from exercising Guanxi by leveraging the relational network as an intangible resource (Bian, 1997; Hwang, 1987; Yen, Tseng, \& Wang, 2014) and by using personal connections to develop competitive advantage and to improve organizational performance (Barnes et al., 2015; Luo, Huang, \& Wang, 2012). Yeung and Tung (1996) regard Guanxi as a key factor for firms to operate successfully in China and essential for relationship marketing (Ambler, 1994). 
The ego-pragmatic view of Guanxi can be explained using the well-established resource-based view (RBV), which defines resources as the "tangible and intangible assets which are tied semipermanently to the firm" and can be used to create sustainable competitive advantage (Wernerfelt, 1984, p.172). In this perspective, Guanxi possesses all the characteristics of being a valuable, rare and imperfectly imitable resource (Barney, 1991, p.106). Guanxi can also be explained using the stakeholder theory (Freeman, 2001) as it helps establish relational bonds between the firm and its stakeholders (e.g., customers, suppliers, investors or even public policy makers) and use these bonds as the basis for long term relationship maintenance (Kull, Mena and Korschun, 2016).

Guanxi may also help improve a firm's performance by allowing it to access unofficial information about regulations and resource availability, and to obtain official consents more swiftly, helping a brand to achieve better sales and to enhance its brand's image (Gu et al., 2008; Luo, 1997; Park \& Luo, 2001; Peng \& Luo, 2000). Guanxi can also bring other benefits to any business, such as facilitating new product development and improving their speed to market (Nan, Na, Lan, \& Yao, 2013), strengthening marketing capabilities (Shou, Chen, Zhu, \& Yang, 2014), improve financial performance as measured by market share, return on assets, return on investment (Gu et al., 2008; Park \& Luo, 2001; Peng \& Luo, 2000) as well as new market development and improving competitive positioning (Park \& Luo, 2001; Yi \& Ellis, 2000). According to Davies et al. (1995), Guanxi 
also helps firms to improve performance by building up their reputation and image in the minds of their key stakeholders. However, most of these studies focus on Guanxi's impact on the firm performance at a strategic level and ignore its use as a strategic or tactical tool to improve individual customers' loyalty behaviors, which may actually have an equally dramatic effect on the firm's performance. This paper addresses this research gap.

\section{Guanxi and Customer Loyalty}

Customer loyalty has been considered the holy grail of marketing because of its long-term impact on a firm's profitability (de Chernatony, 2009). Past research distinguishes between behavioral loyalty, which is demonstrated by repeat purchase and patronage behaviors; and attitudinal loyalty, which involves a deeper psychological involvement of the customers (Day, 1969; Dick \& Basu, 1994; Jacoby \& Chestnut, 1978; Jacoby \& Kyner, 1973; Odin, Odin, \& Valette-Florence, 2001; Oliver, 1999; Tucker, 1964). A recent meta-analysis by Watson, Beck, Henderson and Palmatier (2015, p.791) includes more than 50 definitions of customer loyalty and concludes that the most popular measures of customer loyalty include both attitudinal as well as behavioral loyalty. This distinction between the behavioral and attitudinal aspects of customer loyalty is driven by the belief that the drivers of customer loyalty are a number of higher-order mental constructs or processes, such as cognition-affectconation-action loyalty phases (Jacoby \& Chestnut, 1978; Oliver, Rust, \& Varki, 1997). 
Watson et al. (2015) also find that both attitudinal and behavioral loyalty together have the most optimal impact on objective outcomes, such as revenue and profit (p.803). As a key relational mediator used in Chinese relationship marketing studies, renqing is the cognitive or instrumental component of Guanxi, ganqing is the emotional component of Guanxi and xinren is the trust component of Guanxi (Leung et al., 2008; Leung et al., 2011). Renqing in guanxi plays the role of generating the sense of mutual dependence, obligation and indebtedness between the exchange partners (Wang, Siu \& Barnes, 2008; Yang, 1994). Due to the instrumental nature of renqing, guanxi scholars proposed the use of renqing as a mediator of trust (Shi, Shi, Chan, Liu \& Fam, 2011; Wang et al. 2008). Ganqing is defined as the "measure of the emotional commitment of the parties involved" (Luo, 2007, p.15), closeness of the guanxi (Wang, 2007, p.82), and guanxi must contain the "affect component" rather than purely instrumental (Gold, Gurthie \& Wank, 2002, p.8).

Finally, xinren is a surrogate to the classic notion of trust in relationship marketing studies (Morgan \& Hunt, 1994). Guanxi scholars (Leung et al., 2011; Wang, 2007) argued trust is not an equivalent construct to xinren due to the particularistic and individualistic attribution of personal trust in Chinese society being precedent and transcendence into an organization and supplemental in fulfilling contractual obligations (see Leung et al., 2011, Table 1, p.1196; Shaalan et al., 2013, Figure 2, p.2519). The guanxi dimension is commonly used to test relationship outcomes; such as satisfaction and/or performance (e.g. Barnes, Yen 
\& Zhou, 2011; Luo, 1997; Gu et al. 2008). Arguably in the Chinese cultural context, the impact of Guanxi (renqing-ganqing-xinren) on behavioral loyalty and positive word-ofmouth (WOM) is similar to the cognition-affect-conation loyalty trajectory alluded to by the loyalty scholars in the mainstream relationship marketing literature

The concept of "customer as relationship" from attitudinal loyalty research (de Chernatony, 1998; Fournier, 1998) is also relevant to the investigation of the impact of Guanxi on customer loyalty intentions. Researchers argue that affective traits such as commitment, passion, intimacy and attachment positively affect loyalty intentions (Fournier, 1998; Johnson, Herrmann, \& Huber, 2006; Verhoef, 2003) and financial performance (Duncan \& Elliott, 2002), in addition to other variables, such as customer satisfaction (Anderson, Fornell, \& Lehmann, 1994; Gustafsson, Johnson, \& Roos, 2005; Hallowell, 1996; Oliver, 1997) and service quality (Zeithaml, Berry, \& Parasuraman, 1996). Others show that customers may also put a stronger emphasis on satisfaction and commitment than on trust in determining repeat purchase intentions (Rosenbaum, Massiah, \& Jackson Jr, 2006). However, most of these studies use constructs such as trust, satisfaction, commitment, service quality and perceived value, all of which approach relationship marketing from a Western cultural perspective and ignore culturally deep ingrained phenomena such as Guanxi in China.

In this context, a meta-analysis on relationship marketing effectiveness (Palmatier 
et.al., 2006) suggests that the foremost factor impacting objective performance is "relationship quality", a multidimensional construct that captures the strength of a relationship. This is a better measure than the common unidimensional measures using trust, satisfaction and commitment. Past research on Guanxi also suggests that it can be a reasonable surrogate for overall relationship quality or attitudinal loyalty (Yen et al., 2011). Therefore, instead of testing the individual relational constructs of trust, satisfaction and commitment, this study examines the construct of Guanxi (renqing, xinren and ganqing) and its impact on two (long and short-term) loyalty behavioral outcomes and WOM intentions, with the following specific hypotheses:

H1: Guanxi with a service employee has positive effects on customers' (a) loyalty behavioral intentions and (b) WOM intentions.

\section{Guanxi and Social Ties}

One of the fundamental differences between Chinese and Western relationship marketing practices is that businesses rely on Guanxi to create and maintain relationships, whereas formal contractual ties lead to the need for relationship marketing in the West (Shaalan et al., 2013). A lack of effective institutional support makes Guanxi as an efficient substitute and an important asset for businesses in China (Ambler et al., 1999; Tomás Gómez Arias, 1998;

Wong \& Chan, 1999; Xin \& Pearce, 1996; Yang \& Wang, 2011) because personal 
relationships are explicitly used in Chinese societies as an accepted way to accumulate social capital and resources to identify and capitalize on business opportunities (Michailova \& Worm, 2003; Park \& Luo, 2001). Social ties used in a Chinese context can be for both shortterm tactical and long-term strategic purposes; hence, appropriate Guanxi strategies can be used to target social ties of different strengths (weak or strong) based on the situation (Chen et al., 2013).

In-group bias is another important concept in Guanxi (Tsui \& Farh, 1997). In-groups tend to be fairly stable over time and are found mostly in collectivist societies (Triandis, 1995). In an early sociological study in Chinese context describes Guanxi relationships as links in a Chinese individual's network (Fei, Hamilton, \& Wang, 1992). Hwang (1987, p.150) classifies Guanxi ties into three categories. The first is "instrumental" where it "serves only as a means or an instrument to attain other goals... [and is] basically unstable and temporary. The second is "expressive", a tie that is a "permanent and stable social relationship" formed through affections (p.949). The third, "mixed ties", where relationship is driven by the affective influences of renqing (exchange of favors) and mianzi (giving of face) (Davies et al., 1995; Hwang, 1987). These unique Guanxi ties carry similar but unique traits as compared to strong and weak ties in social network studies (Granovetter, 1983). 
Valuable resources in the form of favors are exchanged within in-groups and being a member of the in-group is important because it helps individuals create and preserve social capital within a closed social network (Coleman, 1988; Coleman \& Coleman, 1994; Xiao \& Tsui, 2007). In this context, Leung et al. (2008) and Wu and Chiu (2016) found that insider (zi-ji-ren) or "old friend" display higher firm-trust and commitment as well as cronyism. A member needs to actively seek membership of an in-group in a Guanxi network in order to achieve business success and survival (Chen, Chang, \& Lee, 2015; Xiao \& Tsui, 2007; Yi \& Ellis, 2000). Based on this, the authors hypothesize that a firm's in-group identification with its customers will help improve their loyalty behavioral and WOM intentions, as follows:

H2: In-group identification with a service employee has positive effects on customers' (a) loyalty behavioral intentions and (b) word-of-mouth intentions.

\section{Guanxi and Calculative Trust}

From a sociological perspective, trust is defined as "a property of collective units (ongoing dyads, groups, and collectivities)" and "being a collective attribute, trust is applicable to the relations among people" (Lewis \& Weigert, 1985, p.968). Trust has a multi-faceted character with distinct cognitive, emotional, and behavioral dimensions which combine with each other to create a unitary social experience (Lewis \& Weigert, 1985). Specifically, the cognitive process underlying trust helps us discriminate people and institutions that are relatively more 
trustworthy than others. In contrast, the affective component of trust represents an emotional bond among all those who participate in the relationship. Finally, the behavioral dimension of trust drives its practical significance through the social action that is influenced by it.

In this context, the idea of calculative trust originates in economics literature, as a cognitive process in which a player weighs the chances of his or her counterpart behaving opportunistically toward him or her. If the player considers the counterpart's opportunistic behavior to be unlikely, calculative trust emerges and the player will stay in the relationship (Akerlof, 1970; Lindskold, 1978; Noorderhaven, 1996). Thus, calculative trust is presented as a form of cognitive trust in business relationships (Johnson \& Grayson, 2005).

For example, Shou et al. (2011) show that calculative trust negatively moderates the effects of trust on the Guanxi behavior, which suggests that calculative trust may be one of the psychological mechanisms that drive the impact of Guanxi on customer loyalty. In other words, members in a Guanxi network may not be there just for affective reasons and instead they may have a well thought-out cognitive plan, to leverage their connections in such a network, to further their own personal interests. Therefore, in this study, the authors use calculative trust as the manifestation of cognitive trust in this study and posit that it mediate the positive effects on Guanxi on loyalty and WOM intentions, as follows:

H3: Calculative trust on a service employee mediates the positive effects of Guanxi 
on customers' (a) loyalty behavioral intentions and (b) word-of-mouth intentions.

\section{Affective Attitudes}

Customer loyalty studies show that affective attitude towards the service provider is a key factor in predicting word-of-mouth intentions (Watson et al. 2015). In contrast, Guanxi is known to be person-specific and cannot be transferred, which makes trust among the partners essential for long-term maintenance of Guanxi networks (Yeung \& Tung, 1996). Hence, it is important to know if the particularistic nature of Guanxi can translate into affective commitment towards the service provider, which would provide an alternative mechanism by which Guanxi could affect customer loyalty. In other words, it is important to test if the customer loyalty created by Guanxi is owned by the salesperson, a concept coined as "Salesperson-owned" loyalty (Palmatier, Scheer, \& Steenkamp, 2007) or it can be transferred to the firm. Accordingly, the following hypothesis is put forth:

H4: Affective attitude toward the service provider mediates the positive effects of Guanxi on customers' (a) loyalty behavioral intentions and (b) word-of-mouth intentions.

Figure 1 summarizes all these hypotheses.

$<$ Insert figure 1 about here $>$ 


\section{METHODOLOGY}

The aim of this study was to investigate the impact of Guanxi between the customers and service providers on customer loyalty and behavioral intentions along with the mediating effects of calculative trust and affective attitude towards the service provider in this process. Therefore, the authors use a field-survey based study to test all the hypotheses, with Chinese retail bank customers whose banking needs are being served by a relationship manager.

This study used a structured questionnaire with all the scales adapted from past research. The questionnaire was developed in English and then translated into Chinese. The Chinese translation was then translated back into English and pre-tested with 20 bank customers to ensure accuracy (Leung et al., 2005). Guanxi was measured as a Reflective Second-order Construct, consisting of its three dimensions - ganqing, renqing and xinren - as recommended by Yen et al., (2011). As this study investigated banking customers, the wording in this scale was revised to substitute "supplier's representative" with "banker" in Yen et al.’s (2011) Guanxi scale. In-group identification scale was adapted from Levin and Sindanius (1999). The original instrument had two questions. A third question was added: "To what extent do your in-group consider this banker as part of the group?"

The mediating variables, calculative trust and affective attitude toward the bank were measured using Shou et al.'s (2011) and Baumann et al.'s (2005) scales respectively. For the 
dependent variables short- and long-term behavioral and word-of-mouth intentions, Baumann et al. (2005) scales were used. The study also recorded gender, age and marital status based on previous Guanxi literature. As the notion of Guanxi may be considered as unethical when personal favors are exchanged (Gu et al., 2008), social desirability scale (Fischer \& Fick, 1993 ) is included to test if such biases exist. All the scales (except social desirability) used seven-point $(1=$ strongly disagree and $7=$ strongly agree $)$ Likert-type response format.

\section{Sample and Data Collection}

The survey was conducted in the People's Republic of China using a face-to-face convenient sampling method by research assistants between February and June 2015. The target participants were bank customers that could identify a banker attending to their core banking needs. The survey asked the participants to give their views about the banker who served them and about the bank that the banker represented. All the respondents were offered 100RMB (approximately US\$15) phone bill credit to encourage participation.

Of the 800 surveys distributed, 420 questionnaires (52.5\% response rate) were used for analysis after excluding incomplete responses and outliers. The final sample is well distributed across gender (male, 46\% and female, 54\%), age (20-39 years, 57\% and 40 years and above, $43 \%$ ) and education (diploma or below, $38 \%$ and bachelor degree or above, $62 \%$ ). Most respondents live in the major cities (17\% Guangzhou, 13\% Shanghai, 12\% Shenzhen, 
and 4-5\% Hangzhou, Fuzhou, Ningbo and Tangshan) and the rest are from 38 smaller cities in China, with less than $4 \%$ contribution from each city. Table 1 shows the sample profile.

$<$ Insert table 1 about here $>$

\section{DATA ANALYSIS AND RESULTS}

The authors deploy the well-established two-step approach with structural equation modelling (SEM) using AMOS 22.0, to test the measurement and structural models (Anderson \& Gerbing, 1988; Byrne, 2010; Kline, 2011). First, confirmatory factor analysis is used to test validity and reliability of all the scales and then structural model analysis helps test all the hypotheses (Byrne, 2010). Mediation effects are tested using the approach recommended by Preacher and Hayes (2004) with 90\% bias corrected bootstrap confidence intervals based on 2,000 bootstrap samples. Post hoc common method bias test was employed using the 'marker variable assessment' technique (Lindell \& Whitney, 2001), wherein social desirability as a marker variable shows no significant correlation with any of the other items. Age, gender and marital status were included in the structural model to control for their effects. Comparing the standardized estimates with and without controls (Becker et al., 2015), shows no significant effect of all these control variables, hence these are not discussed any more in this paper. 


\section{Measurement Model}

Confirmatory Factor Analysis (CFA) uses both Guanxi (comprised of renqing, ganqing and xinren) and loyalty behavior intentions (comprised of Short-term Behavioral Intent and Longterm Behavioral Intent) as second-order reflective constructs and all the other variables in the model as first-order reflective constructs. All the latent constructs were correlated with each other while the measurement items and the error items were constrained to be uncorrelated with each other. After dropping some items with low factor loadings, the final CFA model shows a close fit $\left(\chi^{2}=587.27, d f=297, \chi^{2} / d f=1.98\right.$, GFI $=.91$, IFI $=.96$, TLI $=.95$, CFI $=$ .96$, RMESA $=.048)$. Table 2 shows the descriptive statistics of all the scale items, including those that were deleted.

$<$ Insert table 2 about here $>$

Table 3 shows the correlation matrix and psychometric properties of all the scales. Composite reliability (CR) ranges from .68 to .92 , exceeding the recommended cut-off level of .60 (Bagozzi \& Yi, 1988). Average variance explained (AVE) for all the constructs ranges from .52 to .78 , exceeding the recommended cut-off value of .50 (Bagozzi \& Yi, 1988), which provides evidence of convergent validity. Next, the square root of average variance explained (AVE) for each constructs is higher than its correlations with all the other constructs, which 
supports discriminant validity. Overall, the measurement model provides a good fit to the data and all the scales are valid and reliable according to the well-established norms.

$<$ Insert table 3 about here $>$

\section{Structural Model}

The next step is to test the proposed hypotheses using a structural model, which also shows a close fit $\left(\chi^{2}=60.29, d f=35, \chi^{2} / d f=1.72, \mathrm{GFI}=.95, \mathrm{TLI}=.97, \mathrm{CFI}=.98, \mathrm{RMSEA}=.042\right)$. First, the path coefficient between Guanxi and loyalty behavior is non-significant (.01, $\mathrm{p}$ $>.05)$, hence, H1a is not supported. However, the path coefficient between Guanxi and wordof-mouth is positive and significant $(.15, \mathrm{p}<.05)$, showing support for H1b. Next, in-group identification has a significant positive effect on loyalty behavioral intentions $(.17, \mathrm{p}<.05)$, thus H2a is also supported, but in-group identification has no significant effect on word-ofmouth behavior $(.07, \mathrm{p}>.05)$, hence $\mathrm{H} 2 \mathrm{~b}$ is not supported.

The authors use $90 \%$ bias corrected bootstrap confidence intervals based on 2,000 bootstrap samples (Preacher \& Hayes, 2004) to test the mediating effect of calculative trust in Guanxi's influence on loyalty behavior (H3a: GX $\rightarrow$ CT $\rightarrow$ LBI) and word-of-mouth intentions (H3b: GX $\rightarrow \mathrm{CT} \rightarrow \mathrm{WOM}$ ). First, the effects of GX on LBI through CT are positive (.07 to .27, with a point estimate of $.15, \mathrm{p}<.01)$. Both the direct intermediate paths, GX $\rightarrow \mathrm{CT}(.48, \mathrm{p}<$ $.001)$ and $\mathrm{CT} \rightarrow \mathrm{LBI}(.17, \mathrm{p}<.01)$, are significant while the direct path GX $\rightarrow$ LBI is non- 
significant $(p>.05)$. Thus, calculative trust mediates the effect of Guanxi on loyalty

behaviors (GX $\rightarrow \mathrm{CT} \rightarrow \mathrm{LBI})$, which supports H3a. However, the test for the mediation effect

of calculative trust in Guanxi's effect on word-of-mouth intentions (H3b: GX $\rightarrow \mathrm{CT} \rightarrow$ WOM)

shows no significant indirect effect $(-.04, \mathrm{p}>.05)$, hence H3b is not supported.

Next, the mediation effect of affective attitude toward the bank in the effect of Guanxi on loyalty behavioral intentions ( $\mathrm{H} 4 \mathrm{a}: \mathrm{GX} \rightarrow \mathrm{AAB} \rightarrow \mathrm{LBI})$ finds support, with significant positive effect of GX on LBI through $\mathrm{AAB}(.28$ to .65 , with a point estimate of $.44, \mathrm{p}<.001)$. Both the direct intermediate paths, $\mathrm{GX} \rightarrow \mathrm{AAB}(.52, \mathrm{p}<.001)$ and $\mathrm{AAB} \rightarrow \mathrm{LBI}(.45, \mathrm{p}<.001)$, are also statistically significant while the direct path GX $\rightarrow$ LBI is not significant $(p>.05)$.

Thus, affective attitude toward the bank mediates the effect of Guanxi on loyalty behaviors, which shows support for H4a.

Finally, the mediation effect of affective attitude toward the bank in Guanxi's effect on word-of-mouth intentions ( $\mathrm{H} 4 \mathrm{~b}: \mathrm{GX} \rightarrow \mathrm{AAB} \rightarrow \mathrm{WOM})$ supports partial mediation, with a significant positive effect of GX on WOM through AAB (.37 to .62, with a point estimate of $.48, \mathrm{p}<.001)$. Moreover, both the direct intermediate paths, $\mathrm{GX} \rightarrow \mathrm{AAB}$ and $\mathrm{AAB} \rightarrow \mathrm{WOM}$, are statistically significant $(.56, \mathrm{p}<.001$ and $.62, \mathrm{p}<.001$, respectively) but the direct effect of $\mathrm{GX} \rightarrow$ WOM is also significant $(.16, \mathrm{p}<.05)$. Hence, H4b finds partial support.

$<$ insert table 4 about here $>$ 


\section{DISCUSSION}

This study examines the impact of Guanxi (as reflected by its three components) on customer loyalty and WOM intentions, and the mediating roles of calculative trust and attitude toward the service employee (bank) in this process, while operationalizing the in-group identification construct to gauge in-group membership. The results from a survey-based study with Chinese retail-banking customers confirm that Guanxi does not have a direct effect on loyalty behaviors and instead calculative trust and attitude toward the bank fully mediate this effect. Interestingly, Guanxi has a direct effect on customers' WOM intentions but this effect is not mediated by calculative trust and only partially mediated by affective attitude toward the bank. In-group identification has a positive effect on loyalty behaviors but not on WOM intentions. All these findings support the basic premise of this research that Guanxi has an impact on loyalty behaviors in the Chinese cultural context, while calculative trust and affective attitude toward the service employee and provider mediate this process.

\section{Theoretical Contribution}

This study supports the findings reported in past research about the positive effects of Guanxi on the competitiveness and performance of businesses (Chen et al., 2013; Gu et al., 2008; Luo et al., 2012) by showing two new benefits of Guanxi for businesses, namely loyalty behaviors and word-of-mouth (WOM) behavior. The results of this study also address 
unexplored implications in prior research about how Guanxi may improve a company’s reputation or image (Davies et al., 1995) by showing that Guanxi's effects on loyalty behaviors and WOM behavior could be mediated through calculative trust and affective attitude toward the bank. The finding supplies the missing link in the study by Park and Luo (2001) of the impact of Guanxi on the growth of company sales and net profit, by showing that Guanxi has an effect on loyalty behavior and WOM intentions, which in turn lead to increases in sales and net profit. This research supports Nolan's (2010) and Yen's (2016) recommendation to gain more knowledge of Chinese corporate culture (in particular the banking sector) using Guanxi as a localized relationship marketing strategy.

One key outcome of this study gives the idea that, when dealing with customers from a Chinese cultural background, the Guanxi construct may be more applicable in building relationship than the conventional relationship marketing approach that make use of satisfaction, affective commitment and trust. The finding echoes Shaalan's (2013) analysis of the differences between Guanxi and relationship marketing, which holds that the Chinese and Western concepts of commitment are different. Commitment in Chinese culture is better explained by Guanxi, with its dimensions of ganqing, renqing and xinren.

This study improves our understanding of how Guanxi drives the loyalty behavior of Chinese consumers. The predictions and findings are consistent with attitudinal-loyalty 
theory, where affective attitudes in a relationship drive loyalty behavior (Berry, 2002;

Gustafsson et al., 2005). An important new implication for theory is that Guanxi - an old idea in China, but a new idea in customer loyalty relationship marketing theory - is a powerful affective attitudinal construct that should be used instead of the commonly defined affective commitment construct in relationship marketing literature. This may be particularly relevant when exploring the affective attitudinal commitment relationships of Chinese consumers or those with similar cultural and ethnic backgrounds.

This study also revalidates the Guanxi measurement constructs of renqing, xinren and ganqing (Yen et al., 2011), allowing measurement of Guanxi to be an effective tool in operationalizing the affect-based antecedents to loyalty behavior.

The importance of Guanxi ties, labelled as in-group identification in this study, is well documented in the Guanxi literature, but few empirical tests have validated the relationship between in-group and loyalty behaviors. The operationalization of the in-group identification construct (Levin \& Sidanius, 1999) serves as a good proxy for gauging ingroup membership makes it become another key construct in the Guanxi measurement framework, and tallies with the copious literature that highlights the importance of Guanxi ties in a Guanxi relationship (Hwang, 1987; Leung et al., 2011).

In terms of contribution to word-of-mouth studies, this study argues that Guanxi is the 
key affective attitude driver for customer loyalty and word-of-mouth intentions, and the findings support the notion that Guanxi is an antecedent of word-of-mouth intentions together with the constructs of satisfaction, loyalty, quality, commitment, trust and perceived value (De Matos \& Rossi, 2008, p.579).

It is important to note the similarity of Guanxi to affective commitment. This study also shows that Guanxi has a stronger direct relationship to word-of-mouth than to loyalty behavior, confirming previous research as described in relationship marketing literature, which found affective attitude has a strong impact on word-of-mouth intentions (HenningThurau, Gwinner \& Gremler, 2002).

Calculative trust and affective attitude toward the bank both have full mediation effects for loyalty behavioral intentions, but to a lesser extent for word-of-mouth intentions. Note that affective attitude has more impact on low-involvement decisions, such as a decision to refer a friend to the bank. The idea that affections supplants rationality is, in essence, what is advocated by affective-commitment theories (e.g., Berry, 1995; Gustafsson et al., 2005). When it comes to loyalty behavioral intentions, a more rational approach, calculative trust and a bank's brand (brand affect) come into play. This confirms the dual dimension of emotional/rational attitudes constructs in the relationship marketing literature (e.g., Kumar, Hibbard, \& Stern, 1994; Wetzels, De Ruyter, \& Van Birgelen, 1998). 
Loyalty to salespersons driven by Guanxi can be mediated by building strong

affective attitude toward the bank, but it is important to continue to develop Guanxi, as this would help generate leads for the bank. The results of this study support the notion that affective attitude toward the bank can only partially mediate the influence of Guanxi on word-of-mouth intentions, demonstrating the significance and power of Guanxi. This echoes the phenomenon of sales-loyalty (Palmatier et al., 2007) being an even more important consideration for sales management strategies in emerging markets such as China.

\section{Managerial Implications}

Besides their theoretical contribution, the results of this study also have important implications for marketing managers responsible for devising relationship marketing strategies in emerging markets like China to inculcate customer loyalty behavior in customers. The empirical results support the contention that a one-size-fits-all relationship marketing strategy that works in the West may not work as effectively in the emerging markets like China, particularly in context such as the banking sector, where human interpersonal interactions greatly depend upon Guanxi to overcome the deterrence to sales caused by the complexity of bank products and services.

This study shows that Guanxi is an important driver of customer loyalty and word-ofmouth behaviors. It suggests building Chinese Guanxi relationship is important as a key 
marketing strategy for firms to establish a loyal client base. Notably, the development of Guanxi requires a more sophisticated approach that requires to build Guanxi based on its' deep attitudinal trio constructs of renqing, ganqing and xinren. In addition, Guanxi needs to be developed with strong Guanxi ties, or in-group identification for Guanxi strategy to work.

The fact that Guanxi is mediated by calculative trust and affective attitude towards the bank implies several things. First, it shows that consumers are probably becoming more sophisticated, and they may no longer regard the customary Guanxi practices such as giftgiving as sufficient to establish renqing. The recent official campaigns against corruption in People's Republic of China have also heightened the sensitivity about the propriety of giftgiving and entertainment (Yan, 2014). Marketing managers, should look beyond old Guanxi practices and consider more deeply the push-and-pull factors of renqing, xinren and ganqing and the notion of forming Guanxi network as a priori relationships to ensure success of their customer loyalty campaigns.

A Guanxi social network is a prerequisite for successful relationship marketing in Chinese society. Before relationship marketing can take effect, marketers in China must recognize the importance of the personal links forged by their representatives, to allow Guanxi to play its part. Such bonds should be encouraged because this study shows that Guanxi is more effective when there is in-group identification. Advertising strategies can also 
consider using Guanxi ties in lieu of social ties because these are shown to be very effective in studies on social networking sites in Taiwan (Shen, Chiou, Hsiao, Wanga, \& Li, 2016).

For sales management strategies, the impact of salesperson-owned loyalty should be considered in Chinese context. Guanxi has a strong tendency to diffuse a customer's affective attitude toward the bank; hence, a key relationship marketing strategy could be to teach sales staff proper Guanxi practices to generate leads and foster relationships. Sales managers should adopt measures to retain the sales staff to curate valuable relationships with customers. Managers should also concurrently develop strong company branding strategy to develop brand affect in the minds of customers to counteract salesperson-owned loyalty. Furthermore, strong governance and standardized procedures are required to counteract the effect of calculative trust on the effect of Guanxi on customer loyalty.

To summarize, the findings from this study could be used to recommend a generalized multi-pronged approach for marketers who wish to devise a loyalty management strategy for their Chinese customers. They may begin by incorporating Guanxi as a part of their marketing strategy in general and in their customer loyalty and sales management practices in particular. At the same time, they should try to simultaneously develop a strong brand affect strategy to reduce the chances of their key Guanxi actors (i.e., salespersons) taking customers away with them when they resign. Marketers may also be able to overcome customer 
skepticism or calculative trust by taking strong measures to ensure good governance and quality of service that will counteract any negative mediating effect that calculative trust may have on Guanxi and loyalty behavior. Finally, managers may also use good lead generation and referral processes to build a strong Guanxi network, to help them generate fresh business by leverage positive word-of-mouth intentions from the customers in their Guanxi network.

\section{LIMITATIONS AND FUTURE RESEARCH}

This research has a few limitations. First, the study used convenient sampling, which may lead to potential selection biases unlike random sampling. Hence, future research could use other sampling methods especially if they have access to a sampling frame, such as a list of existing customers of a service organization. Second, the research examines retail-banking relationships only from the customers' perspective, which limits its ability to discern diverse perspectives, such as from the service employees and the management. Future research could use a tripartite survey in order to triangulate the information reported by the customers and the employees with that provided by the service provider's database. Third, this study is one of the first efforts to conceptualize and empirically explore the link between Guanxi in the context of relationship marketing. More future studies with Chinese participants are needed to further test and validate the hypothesized relationships among all the relevant constructs.

Fourth, this study focuses on the retail banking services in China, which may reduce 
the generalizability of its findings; hence, it would be useful to test the model used in this study in other services sector in China. Fifth, Guanxi construct is solely a Chinese cultural phenomenon; hence, the findings of this study may not be applicable to the other cultural contexts. Yet, researchers have already identified constructs similar to Guanxi; such as "blat" in Russia (Michailova \& Worm, 2003), “wa” in Japan and "inhwa” in Korea (Alston, 1989). Hence, it would be useful to investigate the influence of these constructs in the context of relationship marketing, especially their impact on customer loyalty and WOM. Finally, this study measures behavioral intentions rather than actual behavior. Verhoef (2003) recommends the use of longitudinal data rather than self-reported, cross-sectional data to determine loyalty over time and causation of the antecedents to loyalty behaviors.

\section{REFERENCES}

Akerlof, G. (1970). The market for "lemons": Quality uncertainty and the market mechanism. The Quarterly Journal of Economics, 84(3), 488-500. doi:10.1007/978-1-349-24002-9_9

Alston, J. P. (1989). Wa, Guanxi, and inhwa: Managerial principles in Japan, China, and Korea. Business Horizons, 32(2), 26-31.

Ambler, T. (1994). Marketing's third paradigm: Guanxi. Business Strategy Review, 5(4), 6980. doi:10.1111/j.1467-8616.1994.tb00084.x

Ambler, T., Styles, C., \& Xiucun, W. (1999). The effect of channel relationships and Guanxi on the performance of inter-province export ventures in the people's republic of china. International Journal of Research in Marketing, 16(1), 75-87.

Anderson, E. W., Fornell, C., \& Lehmann, D. R. (1994). Customer satisfaction, market share, and profitability: Findings from sweden. The Journal of Marketing,7(1), 53-66. 
Anderson, J. C., \& Gerbing, D. W. (1988). Structural equation modeling in practice: A review and recommended two-step approach. Psychological Bulletin, 103(3), 411-423. doi:10.1037/0033-2909.103.3.411

Bagozzi, R., \& Yi, Y. (1988). On the evaluation of structural equation models. Journal of the Academy of Marketing Science, 16(1), 74-94.

Barney, J. (1991). Firm resources and sustained competitive advantage. Journal of Management, 17(1), 99-120.

Barnes, B. R., Leonidou, L. C., Siu, N. Y., \& Leonidou, C. N. (2015). Interpersonal factors as drivers of quality and performance in western-hong kong interorganizational business relationships. Journal of International Marketing, 23(1), 23-49. doi:http://dx.doi.org/10.1509/jim.14.0008

Barnes, B. R., Yen, D., \& Zhou, L. (2011). Investigating Guanxi dimensions and relationship outcomes: Insights from sino-anglo business relationships. Industrial Marketing Management, 40(4), 510-521.

Batra, R., Ahuvia, A., \& Bagozzi, R. P. (2012). Brand love. Journal of Marketing, 76(2), 116.

Baumann, C., Burton, S., \& Elliott, G. (2005). Determinants of customer loyalty and share of wallet in retail banking. Journal of Financial Services Marketing, 9(3), 231-248.

Becker, T. E., Atinc, G., Breaugh, J. A., Carlson, K. D., Edwards, J. R., \& Spector, P. E. (2015). Statistical control in correlational studies: 10 essential recommendations for organizational researchers. Journal of Organizational Behavior,37(2), 157-167.

Berry, L. L. (2002). Relationship marketing of services-perspectives from 1983 and 2000. Journal of Relationship Marketing, 1(1), 59-78.

Berry, L. L. (1995). Relationship marketing of services--growing interest, emerging perspectives. Journal of the Academy of Marketing Science, 23(4), 236-245.

Bian, Y. (1997). Bringing strong ties back in: Indirect ties, network bridges, and job searches in China. American Sociological Review, 140, 366-385.

Björkman, I., \& Kock, S. (1995). Social relationships and business networks: The case of western companies in China. International Business Review, 4(4), 519-535. 
Byrne, B. M. (2010). Structural equation modeling with AMOS :Basic concepts, applications, and programming (2nd ed.). New York: Routledge.

Carroll, B. A., \& Ahuvia, A. C. (2006). Some antecedents and outcomes of brand love. Marketing Letters, 17(2), 79-89.

Central Intelligence Agency. (2016). The world factbook. Retrieved from https://www.cia.gov/library/publications/resources/the-world-factbook/geos/ch.html

Chen, C. C., Chen, X., \& Huang, S. (2013). Chinese Guanxi: An integrative review and new directions for future research. 中国人的矢系: 综合文献回顾及未来研究方向. Management and Organization Review, 9(1), 167-207.

Chen, M. H., Chang, Y. Y., \& Lee, C. Y. (2015). Creative entrepreneurs' Guanxi networks and success: Information and resource. Journal of Business Research, 68, 900-905.

Chen, X., \& Chen, C. C. (2004). On the intricacies of the chinese Guanxi: A process model of Guanxi development. Asia Pacific Journal of Management, 21(3), 305-324.

Coleman, J. S. (1988). Social capital in the creation of human capital. American Journal of Sociology, 94, 95-120.

Coleman, J. S., \& Coleman, J. S. (1994). Foundations of social theory. MA: Harvard University Press.

Davies, H., Leung, T. K., Luk, S. T., \& Wong, Y. (1995). The benefits of "Guanxi”: The value of relationships in developing the chinese market. Industrial Marketing Management, 24(3), 207-214.

Dawson, M. M. (2005). The ethics of confucius. NY: Cosimo, Inc.

Day, G. (1969). A two-dimensional concept of brand loyalty. Journal of Advertising Research, 9(3), 29-25. doi:10.1007/978-3-642-51565-1_26

de Chernatony, L. (1998). Defining A "brand": Beyond the literature with experts' interpretations. Journal of Marketing Management, 14(5), 417-443.

de Chernatony, L. (2009). Towards the holy grail of defining 'brand'. Marketing Theory, 9(1), 101-105. 
De Matos, C. A., \& Rossi, C. A. V. (2008). Word-of-mouth communications in marketing: A meta-analytic review of the antecedents and moderators. Journal of the Academy of Marketing Science, 36(4), 578-596.

Dick, A. S., \& Basu, K. (1994). Customer loyalty: Toward an integrated conceptual framework. Journal of the Academy of Marketing Science, 22(2), 99-113.

Duncan, E., \& Elliott, G. (2002). Customer service quality and financial performance among Australian retail financial institutions. Journal of Financial Services Marketing, 7(1), 2541.

Farh, J. L., Tsui, A. S., Xin, K., \& Cheng, B. S. (1998). The influence of relational demography and Guanxi: The Chinese Case. Organization Science, 4(9), 471-488.

Fei, X., Hamilton, G. G., \& Wang, Z. (1992). From the soil, the foundations of Chinese society: A translation of Fei Xiaotong's xiangtu zhongguo, with an introduction and epilogue. Berkeley: University of California Press.

Freeman, R., \& McVea, J. (2001). A Stakeholder Approach to Strategic Management. Darden Business School Working Paper No. 01-02. Available at SSRN: https://ssrn.com/abstract=263511 or http://dx.doi.org/10.2139/ssrn.263511

Fischer, D. G., \& Fick, C. (1993). Measuring social desirability: Short forms of the MarloweCrowne social desirability scale. Educational and Psychological Measurement, 53(2), 417-424.

Fournier, S. (1998). Consumers and their brands: Developing relationship theory in consumer research. Journal of Consumer Research, 24(4), 343-373.

Gold, T., Guthrie, D., \& Wank, D. (Eds.). (2002). Social connections in China: Institutions, culture, and the changing nature of guanxi (Vol. 21). Cambridge: Cambridge University Press.

Granovetter, M. (1983). The strength of weak ties: A network theory revisited. Sociological Theory, 1(1), 201.

Gruen, T. W., Summers, J. O., \& Acito, F. (2000). Relationship marketing activities, commitment, and membership behaviors in professional associations. Journal of Marketing, 64(3), 34-49.

Gu, F. F., Hung, K., \& Tse, D. K. (2008). When does Guanxi matter? Issues of capitalization and its dark sides. Journal of Marketing, 72(4), 12-28. 
Gustafsson, A., Johnson, M. D., \& Roos, I. (2005). The effects of customer satisfaction, relationship commitment dimensions, and triggers on customer retention. Journal of Marketing, 69(4), 210-218.

Haley, G. T., Haley, U. C. V., \& Tan, C. T. (2004). The chinese Tao of business (1st ed.). Asia: John Wiley \& Sons.

Hallowell, R. (1996). The relationships of customer satisfaction, customer loyalty, and profitability: An empirical study. International Journal of Service Industry Management, $7(4), 27-42$.

Hennig-Thurau, T., Gwinner, K. P., \& Gremler, D. D. (2002). Understanding relationship marketing outcomes an integration of relational benefits and relationship quality. Journal of Service Research, 4(3), 230-247.

Hofstede, G. (2001). Culture's consequences: Comparing values, behaviors, institutions and organizations across nations. Thousand Oaks: Sage publications.

Hwang, K. (1987). Face and favor: The chinese power game. American Journal of Sociology, 92(4), 944-974.

Jacoby, J., \& Chestnut, R. W. (1978). Brand loyalty: Measurement and management. NY: Wiley.

Jacoby, J., \& Kyner, D. B. (1973). Brand loyalty vs. repeat purchasing behavior. Journal of Marketing Research, 10(1), 1-9.

Johnson, D., \& Grayson, K. (2005). Cognitive and affective trust in service relationships. Journal of Business research, 58(4), 500-507.

Johnson, M. D., Herrmann, A., \& Huber, F. (2006). The evolution of loyalty intentions. Journal of Marketing, 70(2), 122-132. doi:10.1509/jmkg.70.2.122

Kipnis, A. B. (1997). Producing Guanxi: Sentiment, self, and subculture in a North China Village. Durham: Duke University Press.

Kline, R. B. (2011). Principles and practice of structural equation modeling (3rd ed.). New York: Guilford Press.

Kull, A. J., Mena, J. A., \& Korschun, D. (2016). A resource-based view of stakeholder marketing. Journal of Business Research, 69(12), 5553-5560. 
Kumar, N., Hibbard, J. D., \& Stern, L. W. (1994). The nature and consequences of marketing channel intermediary commitment. Cambridge: Marketing Science Institute

Lee, D. Y., \& Dawes, P. L. (2005). Guanxi, trust, and long-term orientation in Chinese business markets. Journal of International Marketing, 13(2), 28-56.

Leung, T., Chan, R. Y., Lai, K., \& Ngai, E. W. (2011). An examination of the influence of Guanxi and xinyong (utilization of personal trust) on negotiation outcome in china: An old friend approach. Industrial Marketing Management, 40(7), 1193-1205.

Leung, T., Heung, V. C., \& Wong, Y. (2008). Cronyism: One possible consequence of Guanxi for an insider: How to obtain and maintain it? European Journal of Marketing, $42(1 / 2), 23-34$.

Leung, T., Lai, K., Chan, R. Y., \& Wong, Y. (2005). The roles of xinyong and Guanxi in chinese relationship marketing. European Journal of Marketing, 39(5/6), 528-559.

Lewis, J. D., \& Weigert, A. (1985). Trust as a social reality. Social forces, 63(4), 967-985.

Levin, S., \& Sidanius, J. (1999). Social dominance and social identity in the United States and Israel: Ingroup favoritism or outgroup derogation? Political Psychology, 20(1), 99126.

Lindell, M. K., \& Whitney, D. J. (2001). Accounting for common method variance in crosssectional research designs. Journal of Applied Psychology, 86(1), 114.

Lindskold, S. (1978). Trust development, the GRIT proposal, and the effects of conciliatory acts on conflict and cooperation. Psychological Bulletin, 85(4), 772-793.

doi:10.1037//0033-2909.85.4.772

Luo, Y. (1997). Guanxi and performance of foreign-invested enterprises in china: An empirical inquiry. MIR: Management International Review,3(1), 51-70.

Luo, Y., Huang, Y., \& Wang, S. L. (2012). Guanxi and organizational performance: A metaanalysis. Management and Organization Review, 8(1), 139-172.

Michailova, S., \& Worm, V. (2003). Personal networking in russia and china:: Blat and Guanxi. European Management Journal, 21(4), 509-519.

Morgan, R. M., \& Hunt, S. D. (1994). The commitment-trust theory of relationship marketing. Journal of Marketing, 58(3), 20-38. doi:10.2307/1252308 
Nan, C., Na, W., Lan, X., \& Yao, Q. (2013). Contingent effects of managerial Guanxi on new product development success. Journal of Business Research, (66), 2522-2528.

Ngobo, P. V. (2016). The trajectory of customer loyalty: An empirical test of Dick and Basu's loyalty framework. Journal of the Academy of Marketing Science, 45(2), 1-22.

Nolan, J. (2010). The influence of western banks on corporate governance in China. Asia Pacific Business Review, 16(3), 417-436.

Noorderhaven, N. G. (1996). Opportunism and trust in transaction cost economics. In J. Groenewegen (Ed.), Transaction cost economics and beyond (pp. 105-128). Boston: Kluwer Academic Publishers.

Odin, Y., Odin, N., \& Valette-Florence, P. (2001). Conceptual and operational aspects of brand loyalty: An empirical investigation. Journal of Business Research, 53(2), 75-84.

Oliver, R. L. (1997). Satisfaction: A behavioral perspective on the customer. New York, McGraw Hill.

Oliver, R. L. (1999). Whence consumer loyalty? The Journal of Marketing, 63, 33-44.

Oliver, R. L., Rust, R. T., \& Varki, S. (1997). Customer delight: Foundations, findings, and managerial insight. Journal of Retailing, 73(3), 311-336.

Palmatier, R. W., Dant, R. P., Grewal, D., \& Evans, K. R. (2006). Factors influencing the effectiveness of relationship marketing: A meta-analysis. Journal of Marketing, 70(4), 136-153.

Palmatier, R. W., Scheer, L. K., \& Steenkamp, J. E. (2007). Customer loyalty to whom? managing the benefits and risks of salesperson-owned loyalty. Journal of Marketing Research, 44(2), 185-199.

Park, S. H., \& Luo, Y. (2001). Guanxi and organizational dynamics: Organizational networking in chinese firms. Strategic Management Journal, 22(5), 455-477.

Peng, M. W., \& Luo, Y. (2000). Managerial ties and firm performance in a transition economy: The nature of a micro-macro link. Academy of Management Journal, 43(3), 486-501.

Preacher, K. J., \& Hayes, A. F. (2004). SPSS and SAS procedures for estimating indirect effects in simple mediation models. Behavior Research Methods, Instruments, \& Computers, 36(4), 717-731. 
Reichheld, F. F. (1990). Zero defections: Quality comes to services. Harvard Business Review, 68(5), 105-111.

Rosenbaum, M. S., Massiah, C., \& Jackson Jr, D. W. (2006). An investigation of trust, satisfaction, and commitment on repurchase intentions in professional services. Services Marketing Quarterly, 27(3), 115-135.

Samaha, S. A., Beck, J. T., \& Palmatier, R. W. (2014). The role of culture in international relationship marketing. Journal of Marketing, 78(5), 78-98.

Samiee, S., Chabowski, B. R., \& Hult, G. T. M. (2015). International relationship marketing: Intellectual foundations and avenues for further research. Journal of International Marketing, 23(4), 1-21.

Shaalan, A. S., Reast, J., Johnson, D., \& Tourky, M. E. (2013). East meets west: Toward a theoretical model linking Guanxi and relationship marketing. Journal of Business Research, 66(12), 2515-2521.

Sharma, P. (2010). Measuring personal cultural orientations: Scale development and validation. Journal of the Academy of Marketing Science, 38(6), 787-806.

Sharma, P. (2011). Country of origin effects in developed and emerging markets: Exploring the contrasting roles of materialism and value consciousness. Journal of International Business Studies, 42(2), 285-306.

Shen, G. C., Chiou, J., Hsiao, C., Wanga, C., \& Li, H. (2016). Effective marketing communication via social networking site the moderating role of the social tie. Journal of Business Research, 69(6), 2265-2270.

Shi, G., Shi, Y., Chan, A. K., Liu, M. T., \& Fam, K. S. (2011). The role of renqing in mediating customer relationship investment and relationship commitment in China. Industrial Marketing Management, 40(4), 496-502.

Shou, Z., Chen, J., Zhu, W., \& Yang, L. (2014). Firm capability and performance in china: The moderating role of Guanxi and institutional forces in domestic and foreign contexts. Journal of Business Research, 67(2), 77-82.

Shou, Z., Guo, R., Zhang, Q., \& Su, C. (2011). The many faces of trust and Guanxi behavior: Evidence from marketing channels in China. Industrial Marketing Management, 40(4), 503-509. 
Tomás Gómez Arias, J. (1998). A relationship marketing approach to Guanxi. European Journal of Marketing, 32(1/2), 145-156.

Triandis, H. C. (1995). Individualism \& collectivism. Boulder: Westview press.

Tsui, A. S., \& Farh, J. L. (1997). Where Guanxi matters relational demography and Guanxi in the Chinese context. Work and Occupations, 24(1), 56-79.

Tucker, W. T. (1964). The development of brand loyalty. Journal of Marketing Research,1(8), 32-35.

Verhoef, P. C. (2003). Understanding the effect of customer relationship management efforts on customer retention and customer share development. Journal of Marketing, 6720084), 30-45.

Wang, C. L. (2007). Guanxi vs. relationship marketing: Exploring underlying differences. Industrial Marketing Management, 36(1), 81-86.

Wang, C. L., Siu, N. Y., \& Barnes, B. R. (2008). The significance of trust and renqing in the long-term orientation of Chinese business-to-business relationships. Industrial Marketing Management, 37(7), 819-824

Watson, G. F., Beck, J. T., Henderson, C. M., \& Palmatier, R. W. (2015). Building, measuring, and profiting from customer loyalty. Journal of the Academy of Marketing Science, 43(6), 790-825.

Wernerfelt, B. (1984). A resource-based view of the firm. Strategic Management Journal, 5(2), 171-180.

Wetzels, M., De Ruyter, K., \& Van Birgelen, M. (1998). Marketing service relationships: The role of commitment. Journal of Business \& Industrial Marketing, 13(4/5), 406-423.

Wong, Y., \& Chan, R. Y. (1999). Relationship marketing in china: Guanxi, favouritism and adaptation. Journal of Business Ethics, 22(2), 107-118.

Wu, W., \& Chiu, S. W. (2016). The impact of Guanxi positioning on the quality of manufacturer-retailer channel relationships. Journal of Business Research, 69(9), 33983405. doi:10.1016/j.jbusres.2016.02.004

Xiao, Z., \& Tsui, A. S. (2007). When brokers may not work: The cultural contingency of social capital in Chinese high-tech firms. Administrative Science Quarterly, 52(1), 1-31. 
Xin, K. R., \& Pearce, J. L. (1996). Guanxi: Connections as substitutes for formal institutional support. Academy of Management Journal, 39(6), 1641-1658.

Yan, S. (2014). China's anti-corruption drive eats into growth. Retrieved from http://money.cnn.com/2014/01/28/news/economy/china-anti-corruption/index.html

Yang, M. M. H. (1994). Gifts, Favors, and Banquets: The Art of Social Relationships in China. Ithaca, NY: Cornell University Press.

Yang, Z., \& Wang, C. L. (2011). Guanxi as a governance mechanism in business markets: Its characteristics, relevant theories, and future research directions. Industrial Marketing Management, 40(4), 492-495.

Yau, O. H., Lee, J. S., Chow, R. P., Sin, L. Y., \& Tse, A. C. (2000). Relationship marketing the Chinese way. Business Horizons, 43(1), 16-24.

Yen, D. A., \& Anpsag, I. (2016). Localization in china: How Guanxi moderates Sino-US business relationships. Journal of Business Research, (69), 5724-5734. doi:10.1016/j.jbusres.2016.05.002

Yen, D. A., Barnes, B. R., \& Wang, C. L. (2011). The measurement of Guanxi : Introducing the GRX scale. Industrial Marketing Management, 40(1), 97-108.

Yen, Y., Tseng, J., \& Wang, H. (2014). Exploring the mediating role of trust on the relationship between Guanxi and knowledge sharing: A social network perspective. Asia Pacific Journal of Human Resources, 52(2), 173.

Yeung, I. Y. M., \& Tung, R. L. (1996). Achieving business success in confucian societies: The importance of Guanxi (connections). Organizational Dynamics, Autumn (1996), 5465.

Yi, L. M., \& Ellis, P. (2000). Insider-outsider perspectives of Guanxi. Business Horizons, 43(1), 25-30.

Zeithaml, V. A., Berry, L. L., \& Parasuraman, A. (1996). The behavioral consequences of service quality. The Journal of Marketing, April(60), 31-46. 
Figure 1 - Conceptual Model

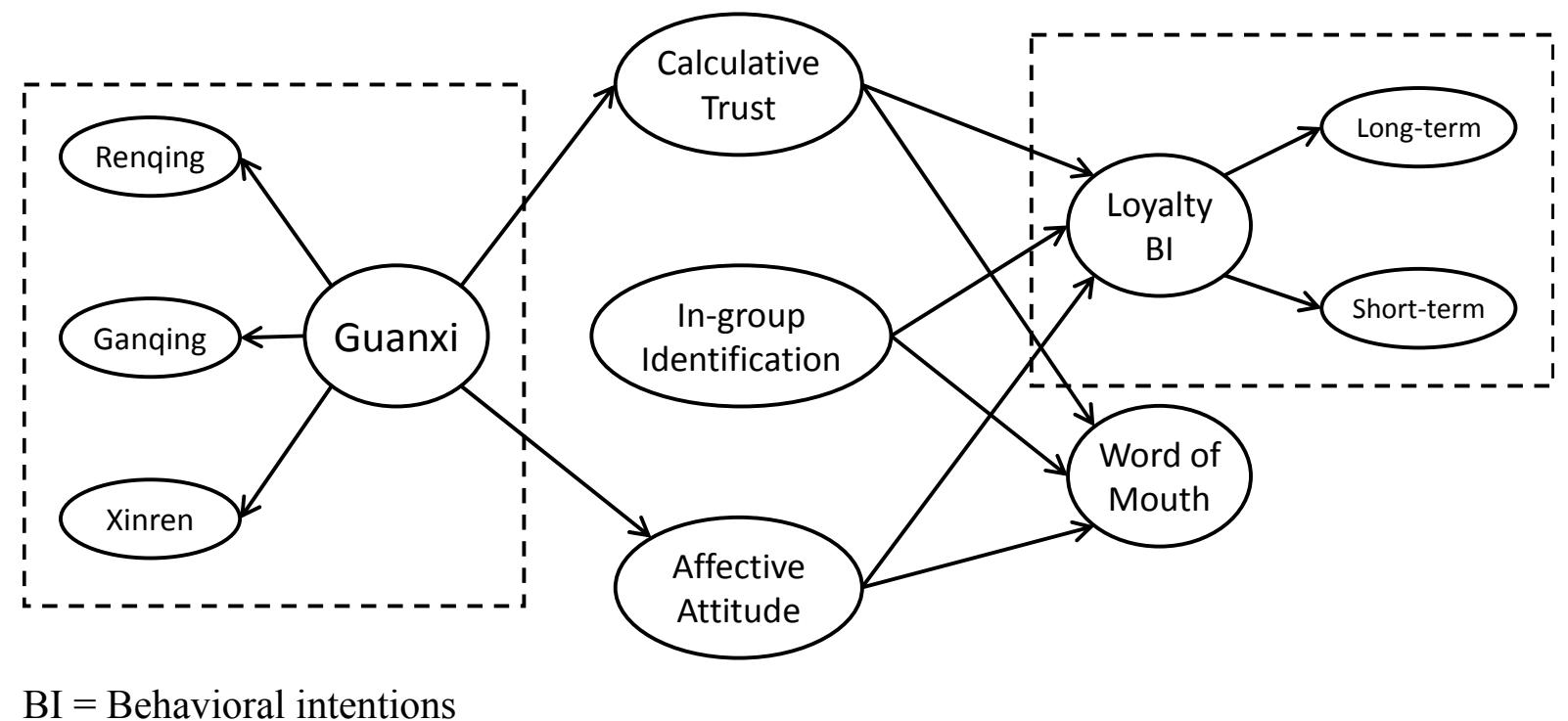


Table 1 - Demographic Profile of the Respondents $(\mathrm{N}=420)$

\begin{tabular}{llllll}
\hline Description & & $\mathbf{\%}$ & Description & & $\%$ \\
\hline Gender & Male & $46.4 \%$ & Age & $20-29$ & $32.3 \%$ \\
& Female & $53.6 \%$ & & $30-39$ & $24.4 \%$ \\
& Accounting and Finance & $17.3 \%$ & & $40-49$ & $27.2 \%$ \\
& Civil service & $14.2 \%$ & $50-59$ & $11.8 \%$ \\
& Administration & $9.1 \%$ & & $60+$ & $4.3 \%$ \\
& Entrepreneur & $8.4 \%$ & Residence & Guangzhou & $17.2 \%$ \\
& Advertising and media & $5.0 \%$ & & Shanghai & $13.5 \%$ \\
& Others & $<5 \%$ & & Shenzhen & $12.2 \%$ \\
& Junior high school & $5.1 \%$ & & Hangzhou & $4.6 \%$ \\
& High school & $12.3 \%$ & & Fuzhou & $4.5 \%$ \\
& Diploma & $20.7 \%$ & & Ningbo & $4.4 \%$ \\
& Bachelor's degree & $47.5 \%$ & & Tangshan & $4.2 \%$ \\
& Master's or higher & $14.4 \%$ & & Others & $<4 \%$ \\
\hline
\end{tabular}


Table 2 - Confirmatory factor analysis of tested constructs

\begin{tabular}{|c|c|c|c|}
\hline Scales Items & $\lambda$ & $\mathbf{M}$ & SD \\
\hline \multicolumn{4}{|l|}{ Guanxi (Yen et al., 2011) } \\
\hline Renqing (RQ) & .80 & 3.71 & 1.39 \\
\hline 1. I feel a sense of obligation to this banker for doing him/her a favor & .76 & 3.85 & 1.35 \\
\hline 2. I think that calling in favors is part of doing business with this banker. & .88 & 3.68 & 1.47 \\
\hline 3. The practice of give and take of favors is a key part of the relationship between this banker and me. & .81 & 3.59 & 1.45 \\
\hline Ganqing (GQ) & .89 & 3.97 & 1.42 \\
\hline 1. This banker and I are able to talk openly as friends & .77 & 4.12 & 1.47 \\
\hline 2. If I were to change this banker, I would lose a good friend. & .65 & 3.69 & 1.45 \\
\hline 3. I would consider whether this banker's feelings would be hurt before I made an important decision. & .80 & 3.93 & 1.34 \\
\hline 4. I would try my best to help out this banker when he/she is in need because he/she is a friend of mine. & .79 & 4.14 & 1.37 \\
\hline Xinren $(X R)$ & .73 & 4.20 & 1.24 \\
\hline 1. This banker is only concerned about himself/herself. (R) & .67 & 4.21 & 1.25 \\
\hline 2. The people in my social network do not trust this banker. (R) & .78 & 4.18 & 1.21 \\
\hline 3. This banker is trustworthy. - Deleted & .37 & 3.65 & 1.24 \\
\hline In-group identification (IG) (Levin and Sindanius., 1999) & & 3.07 & 1.30 \\
\hline 1. To what extent do you identify this banker with other members of your in-group? & .84 & 3.12 & 1.28 \\
\hline 2. To what extent do you feel this banker is close to other members of your in-group? & .86 & 2.98 & 1.32 \\
\hline 3. To what extent do your in-group consider this banker as part of the group? & .88 & 3.11 & 1.30 \\
\hline Calculative trust (CT) (Shou et al., 2011) & & 4.63 & 1.25 \\
\hline 1. This banker realizes that not being opportunistic accords with their interest. & .68 & 4.44 & 1.28 \\
\hline 2. This banker realizes that violating our trust will certainly be sanctioned. & .74 & 4.51 & 1.29 \\
\hline
\end{tabular}


3. Since the cost of defection is high, I believe that this banker would not be opportunistic.

Loyalty behavior intentions (LBI)

Short-term loyalty behavior (STBI) (Baumann et al., 2005)

1. It is very unlikely that I will close an account with this bank within the next six months

2. It is very unlikely that I will choose a product from another bank in the next six months.

3. It is very unlikely that I will close an account with this bank within the next six months.

1. I would stay with this bank even if competitors offered lower charges and/or better interest rates.

2. If I saw an attractive offer in another bank branch, I would leave this bank. (R) - Deleted

3. In five years' time, I expect that I will still be doing most banking with this current bank.

Affective attitude toward the bank (Baumann et al., 2005)

1. I like this bank

2. I enjoy visiting this bank.

3. I feel good about this bank.

4. I have a sense of belonging to this bank.

Word-of-mouth (Baumann et al., 2005)

1. If other people inquired about this bank then I would recommend it.

2. I am happy to voluntarily recommend this bank to others.

3. This is the bank which I refer the most to my friend.

$\lambda=$ Standardized factor loading, $\mathrm{M}=$ Mean, $\mathrm{SD}=$ Standard Deviation, $\mathrm{R}=$ Reverse Scale

Note: Items in italics were removed due to their poor psychometric properties. Items in bold represent the higher order factor loadings. 
Table 3 - Correlations Table \& Descriptive Statistics

\begin{tabular}{|c|c|c|c|c|c|c|c|c|c|}
\hline & RQ & GQ & XR & IG & $\mathrm{CT}$ & STBI & LTBI & $\mathrm{AAB}$ & WOM \\
\hline RQ & .82 & & & & & & & & \\
\hline GQ & $.73^{* *}$ & .75 & & & & & & & \\
\hline XR & $.30^{* *}$ & $.26^{* *}$ & .73 & & & & & & \\
\hline $\mathrm{IG}$ & $.53^{* *}$ & $.56^{* *}$ & $.32^{* *}$ & .86 & & & & & \\
\hline $\mathrm{CT}$ & $.36^{* *}$ & $.43^{* *}$ & $.31^{* *}$ & $.32^{* *}$ & .75 & & & & \\
\hline STBI & $.17^{* *}$ & $.26^{* *}$ & $.22^{* *}$ & $.21^{* * *}$ & $.28^{* *}$ & .80 & & & \\
\hline LTBI & $.22^{* *}$ & $.32^{* *}$ & $.22^{* *}$ & $.36^{* *}$ & $.31^{* *}$ & $.49^{* *}$ & .72 & & \\
\hline $\mathrm{AAB}$ & $.41^{* *}$ & $.45^{* *}$ & $.31^{* *}$ & $.39^{* * *}$ & $.40^{* *}$ & $.37^{* *}$ & $.40^{* *}$ & .86 & \\
\hline WOM & $.38^{* *}$ & $.44^{* *}$ & $.33^{* *}$ & $.41^{* *}$ & $.32^{* *}$ & $.43^{* *}$ & $.42^{* *}$ & $.70^{* *}$ & .88 \\
\hline $\mathrm{M}$ & 3.71 & 3.97 & 4.20 & 3.07 & 4.63 & 5.01 & 4.29 & 5.16 & 4.84 \\
\hline SD & 1.39 & 1.42 & 1.24 & 1.30 & 1.25 & 1.27 & 1.33 & 1.21 & 1.19 \\
\hline AVE & .67 & .57 & .53 & .74 & .56 & .64 & .52 & .73 & .78 \\
\hline $\mathrm{CR}$ & .86 & .84 & .69 & .90 & .79 & .84 & .68 & .92 & .91 \\
\hline
\end{tabular}

Note: Figures on the diagonal (in bold) are the square roots of AVE (to test discriminant validity). 
Table 4 - Hypotheses Testing - Structural Model $(\mathrm{N}=420)$

\begin{tabular}{|c|c|c|c|c|c|}
\hline & Path & Std. Est. & \multicolumn{3}{|c|}{ Results } \\
\hline H1a & $\mathrm{GX} \rightarrow \mathrm{LBI}$ & .01 & \multicolumn{3}{|c|}{ Not supported, fully mediated } \\
\hline $\mathrm{H} 1 \mathrm{~b}$ & $\mathrm{GX} \rightarrow \mathrm{WOM}$ & $.15^{*}$ & \multicolumn{3}{|c|}{ Supported } \\
\hline $\mathrm{H} 2 \mathrm{a}$ & $\mathrm{IG} \rightarrow \mathrm{LBI}$ & $.17^{*}$ & \multicolumn{3}{|c|}{ Supported } \\
\hline $\mathrm{H} 2 \mathrm{~b}$ & $\mathrm{IG} \rightarrow \mathrm{WOM}$ & .07 & \multicolumn{3}{|c|}{ Not supported } \\
\hline & Path & Std. Est. & $\mathrm{CI}_{\text {low }}$ & $\mathrm{CI}_{\text {high }}$ & Results \\
\hline $\mathrm{H} 3 \mathrm{a}$ & $\mathrm{GX} \rightarrow \mathrm{CT} \rightarrow \mathrm{LBI}$ & $.15^{* *}$ & .07 & .27 & Full mediation \\
\hline $\mathrm{H} 3 \mathrm{~b}$ & $\mathrm{GX} \rightarrow \mathrm{CT} \rightarrow \mathrm{WOM}$ & -.04 & -.11 & .07 & No mediation \\
\hline $\mathrm{H} 4 \mathrm{a}$ & $\mathrm{GX} \rightarrow \mathrm{AAB} \rightarrow \mathrm{LBI}$ & $.44 * * *$ & .28 & .65 & Full mediation \\
\hline $\mathrm{H} 4 \mathrm{~b}$ & $\mathrm{GX} \rightarrow \mathrm{AAB} \rightarrow \mathrm{WOM}$ & $.48^{* * *}$ & .37 & .62 & Partial mediation \\
\hline \multicolumn{6}{|c|}{ Structural Model Fit: $\chi^{2} / \mathrm{df}=1.72, \mathrm{GFI}=.95, \mathrm{TLI}=.97, \mathrm{CFI}=.98 \mathrm{RMSEA}=.042$} \\
\hline
\end{tabular}

